\title{
Effect of omeprazole on the expression of transcription factors in osteoclasts and osteoblasts
}

\author{
JONG JIN HYUN ${ }^{1}$, HOON JAI CHUN ${ }^{1}$, BORA KEUM ${ }^{1}$, YEON SEOK SEO ${ }^{1}$, YONG SIK KIM ${ }^{1}$, \\ YOON TAE JEEN ${ }^{1}$, HONG SIK LEE ${ }^{1}$, SOON HO UM ${ }^{1}$, CHANG DUCK KIM ${ }^{1}$, \\ HO SANG RYU ${ }^{1}$, SIN GON KIM ${ }^{2}$ and WOON-WON JUNG ${ }^{3}$
}

\begin{abstract}
Divisions of ${ }^{1}$ Gastroenterology and Hepatology and ${ }^{2}$ Endocrinology and Metabolism, Department of Internal Medicine, Korea University Anam Hospital; ${ }^{3}$ College of Health Science, Korea University, Seoul, Korea
\end{abstract}

Received July 6, 2010; Accepted September 2, 2010

DOI: $10.3892 /$ ijmm_00000537

\begin{abstract}
The use of proton pump inhibitors (PPIs) seems to be related to increased fracture risk but the mechanism is unclear. In an effort to clarify the mechanism, we evaluated the effect of omeprazole, a representative of the PPIs, on the expression of transcription factors in osteoclasts and osteoblasts. Murine RAW264.7 and MC3T3-E1 cells were used for osteoclast and osteoblast analysis, to which various concentrations of omeprazole were added. RAW264.7 cells with $\geq 3$ nuclei were considered tartrate-resistant acid phosphatase (TRAP)-positive, i.e. activated osteoclasts. Expressions of the calcitonin receptor (CTR), c-fos, nuclear factor of activated T-cells, cytoplasmic 1 (NFATc1), and matrix metalloproteinase (MMP)-9 mRNA in osteoclasts were evaluated. Gene expression of osteocalcin and of the osteoprotegerin/receptor activator of NF- $\mathrm{B}$ ligand (OPG/RANKL) ratio in osteoblasts was examined and Western blotting of NFATc1 was performed. Treating the osteoclasts with increasing doses of omeprazole did not affect TRAP positivity, but significantly decreased the expressions of CTR, c-fos, NFATc1, and MMP-9 regardless of the omeprazole concentration. The expression of osteocalcin and of the OPG/RANKL ratio in osteoblasts was augmented with increasing omeprazole concentrations. The result of the Western blot analysis with NFATc1 was similar to that of the expression of NFATc1 mRNA. Omeprazole decreased the activation of osteoclasts but increased that of osteoblasts in vitro, in part causing an osteopetrosis-like
\end{abstract}

Correspondence to: Dr Hoon Jai Chun, Division of Gastroenterology and Hepatology, Department of Internal Medicine, Korea University Anam Hospital, 126-1, Anamdong 5-ga, Seongbukgu, Seoul 136-705, Korea

E-mail: drchunhj@chol.com

Key words: proton pump inhibitor, omeprazole, osteoclast, osteoblast effect. Together with the effect of omeprazole on calcium homeostasis, increased fracture risk may be due to the osteopetrorickets-like effect of omeprazole.

\section{Introduction}

The use of the proton pump inhibitors (PPIs) has markedly increased over the past two decades and they are the main drug used for treating gastroesophageal reflux disease $(1,2)$, they are essential in curing peptic ulcer disease (3) and play an important role in managing functional dyspepsia (4). PPIs have been shown to be very effective and are considered to carry little risk of developing adverse effects, thus favoring their use for a long duration by those with chronic debilitating conditions. However, data are accumulating on their possible side effects, such as community-acquired pneumonia (5) and community-acquired Clostridium-difficileassociated disease (6). PPIs have also been implicated in increasing the risk of bone fractures (7-12). Yang et al reported that there was a correlation between long-term PPI therapy and an increased risk of hip fracture, particularly at high doses (7). Targownik et al demonstrated that there was a significant increase in osteoporosis-related fractures after 7 or more years of PPI use and an increased risk of hip fracture after 5 or more years of continuous exposure (8). Vestergaard et al reported that PPI use was associated with an increased risk of bone fracture, even though the association was only marginal (9). Based on the observation of several epidemiological studies (7-12), the U.S. Food and Drug Administration decided to add the safety information about the possible increased risk of bone fracture in the prescription and overthe-counter labels for PPIs.

The use of PPIs could increase the risk of bone fractures by affecting calcium homeostasis, which can either be due to inhibition of calcium absorption $(13,14)$ or to the induction of hyperparathyroidism secondary to the development of hypergastrinemia $(15,16)$, although controversy remains. Since PPIs block the acid secretion not only in parietal cells but also in osteoclasts, an essential step in bone resorption (17-19), they could theoretically decrease the risk of bone fractures and be osteoprotective. Nevertheless, the results of several large population-based studies have shown that PPIs 
are not osteoprotective. Therefore, this study was conducted to evaluate the effects of omeprazole, a representative of the PPIs, on the expression of the transcription factors in osteoclasts in order to shed light on the involvement of PPIs in bone metabolism. In addition, we also investigated the effect of omeprazole on osteoblasts.

\section{Materials and methods}

Materials. Glycerophosphate, ascorbic acid, receptor activator of NF-кB ligand (RANKL), and omeprazole were purchased from Sigma Chemical (St. Louis, MO, USA). $\alpha$-modified minimal essential medium ( $\alpha$-MEM; Gibco BRL, Grand Island, NY, USA), trypsin-EDTA, penicillin, and streptomycin were acquired from Gibco Invitrogen (Grand Island, NY, USA). Fetal bovine serum (FBS) was purchased from HyClone (Logan, UT, USA). Culture dishes and plastic labware were from BD Falcon (Franklin Lakes, NJ, USA). All chemicals related to real-time (RT) PCR were purchased from Roche Molecular Biochemicals (Germany).

Cell culture. For osteoblast analysis, murine MC3T3-E1 cells were cultured in 6-well plates at $37^{\circ} \mathrm{C}$ and $5 \% \mathrm{CO}_{2}$ atmosphere with $\alpha$-MEM containing $10 \%$ heat-inactivated FBS, $100 \mathrm{U} / \mathrm{ml}$ penicillin and $100 \mu \mathrm{g} / \mathrm{ml}$ streptomycin. The cells in 6-well plates were grown to $90 \%$ confluence and treated with culture medium containing $10 \mathrm{mM}$ ß-glycerophosphate and $50 \mathrm{ng} / \mathrm{ml}$ ascorbic acid to induce osteoblast differentiation.

For osteoclast analysis, murine RAW 264.7 cells were cultured with the same method used for the osteoblast analysis except for the use of $50 \mathrm{ng} / \mathrm{ml}$ of RANKL as a stimulant in order to induce osteoclast differentiation. To determine the effect of omeprazole on osteoblasts and osteoclasts, various concentrations of omeprazole $(0.1,1,2$ and $4 \mu \mathrm{g} / \mathrm{ml}$ ) were added to the culture medium at the time of osteoblast or osteoclast differentiation. The cell culture medium was changed every 2 or 3 days.

\section{3-(4,5-Dimethylthiazol-2-yl)-2,5-diphenyltetrazolium bromide salt (MTT) assay. Cell viability was tested using a colorimetric assay based on the uptake of MTT by viable cells (20). In brief, a solution of MTT $(0.5 \mathrm{mg} / \mathrm{ml})$ was added to the cells followed by incubation at $37^{\circ} \mathrm{C}$ to form blue formazan crystals. After $3 \mathrm{~h}$, the residual MTT was carefully removed and the crystals were dissolved by incubation with DMSO for $30 \mathrm{~min}$. The plates were then shaken for $5 \mathrm{~min}$ and the absorbance was measured at $570 \mathrm{~nm}$ with spectro- photometry.}

Tartrate-resistant acid phosphatase (TRAP) assay. The TRAP assay was conducted using the TRAP cytochemical stain technique as previously described (21). In brief, cells were washed once with PBS and fixed in $10 \%$ formalin for 10 min. After washing with PBS, cells were permeabilized with $0.1 \%$ Triton $\mathrm{X}-100$ for 1 min, washed once with PBS, and incubated with the substrate solution, napthol AS-BI phosphate (Sigma) in the presence of $50 \mathrm{mM}$ sodium tartrate at $37^{\circ} \mathrm{C}$ for $10 \mathrm{~min}$. Resulting red-stained TRAP activity was visualized by light microscopy. To quantify TRAP activity, TRAP-positive cells with 3 or more nuclei were counted.
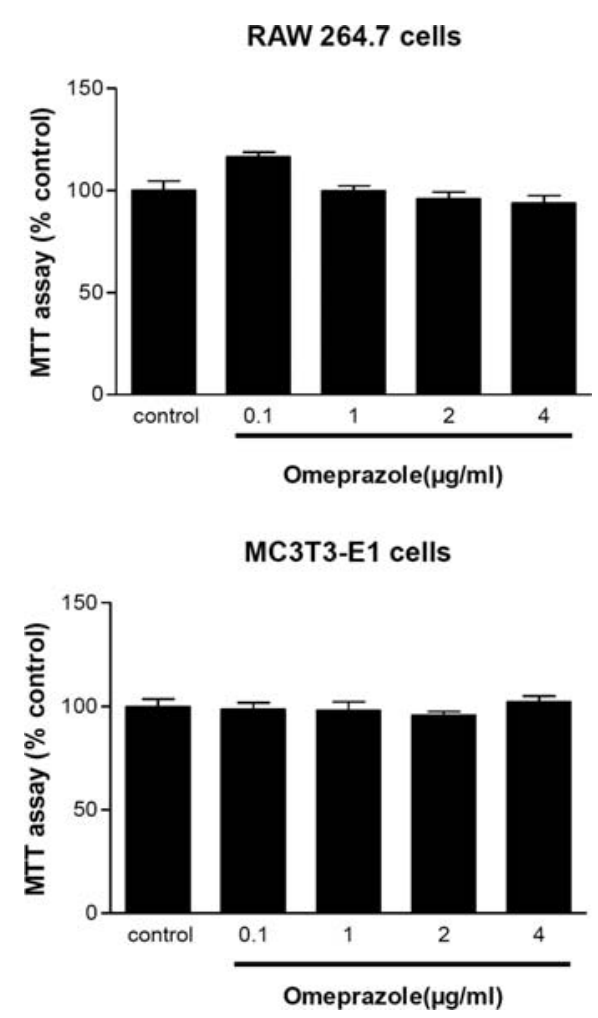

Figure 1. Effect of different concentrations of omeprazole on the viability of RAW 264.7 cells and MC3T3-E1 cells. Cell viability was measured through the MTT assay. Each bar represents the number of cells in percentage compared to the control and shows that omeprazole has no significant effect on the viability of RAW 264.7 cells and MC3T3-E1 cells.

Gene expression. The total cellular RNA was extracted using RNeasy kit (Qiagen, Santa Clarita, CA, USA) according to the manufacturer's instructions. Aliquots $(1 \mu \mathrm{g})$ of total RNA were retro-transcribed into cDNA at $42^{\circ} \mathrm{C}$ for $1 \mathrm{~h}$ in a total volume of $20 \mu \mathrm{l}$ with the first strand cDNA synthesis kit (Roche Diagnostics GmbH, Mannheim, Germany). RT-PCR was performed to verify the differential expression of selected genes using a Roche LightCycler 480 system (Roche Diagnostics $\mathrm{GmbH}$ ) and the Taqman method using the Roche Universal ProbeLibrary (UPL) kit. All reactions were carried out in a total volume of $20 \mu \mathrm{l}$ of reaction mixture containing $10.0 \mu \mathrm{l}$ of $2 \mathrm{X}$ UPL master mix, $1.0 \mu \mathrm{l}$ of $5^{\prime}$ primer $(10 \mathrm{pmol} /$ $\mu \mathrm{l}), 1.0 \mu \mathrm{l}$ of $3^{\prime}$ primer $(10 \mathrm{pmol} / \mathrm{ml}), 0.2 \mu \mathrm{l}$ of UPL probe, $1.0 \mu 1$ of cDNA and $6.8 \mu 1$ of sterile water. The thermal cycling conditions for PCR were an initial denaturation for $10 \mathrm{~min}$ at $95^{\circ} \mathrm{C}$, followed by 40 cycles at $60^{\circ} \mathrm{C}$ for $10 \mathrm{sec}$ and at $72^{\circ} \mathrm{C}$ for $30 \mathrm{sec}$. The sequences of the primers shown in Table 1 were designed by the Roche ProbeFinder assay tool. For the RT-PCR analysis, triplicate PCRs were carried out for each cDNA. Negative controls were included in the PCR reaction to ensure specific amplification. The values obtained from each sample were normalized to HPRT expression. LightCycler 480 software version 1.2 (Roche) was used for the analysis of the quantitative PCR. Relative gene expression was determined by employing the comparative CT method (22).

Western blot analysis. Cultured cells were solubilized in lysis buffer [150 mM NaCl, 20 mM Tris-HCl (pH 7.4), 0.1\% SDS, 
Table I. Genes and primers for gene expression.

\begin{tabular}{ll}
\hline Gene & \multicolumn{1}{c}{ Sequence } \\
\hline HPRT & 5'-TCC TCC TCA GAC CGC TTT T-3' \\
Hypoxanthine-guanine phosphoribosyltransferase & 5'-CCT GGT TCA TCA TCG CTA ATC-3' \\
Osteocalcin & 5'-CAC CAT GAG GAC CCT CTC TC-3' \\
& 5'-TGG ACA TGA AGG CTT TGT CA-3' \\
RANKL & 5'-CTG ATG AAA GGA GGG AGC AC-3' \\
Receptor activator of nuclear factor kB ligand & 5'-GAA GGG TTG GAC ACC GTA ATG C-3' \\
OPG & 5'-GTT TCC CGA GGA CCA CAA T-3' \\
Osteoprotegerin & 5'-CCA TTC AAT GAT GTC CAG GAG-3' \\
c-Fos & 5'-CAG CCT TTC CTA CTA CCA TTC C-3' \\
& 5'-ACA GAT CTG CGC AAA AGT CC-3' \\
NFATc1 & 5'-TCC AAA GTC ATT TTC GTG GA-3' \\
Nuclear factor of activated T-cells, cytoplasmic 1 & 5'-CTT TGC TTC CAT CTC CCA GA-3' \\
MMP-9 & 5'-ACG ACA TAG ACG GCA TCC A-3' \\
Matrix metalloproteinase-9 & 5'-GCT GTG GTT CAG TTG TGG TG-3' \\
CTR & 5'-GGT TCC TTC TCG TGA ACA GGT-3' \\
Calcitonin receptor & 5'-AGA ACT GGA GTT GGG CTC AC-3' \\
\hline
\end{tabular}
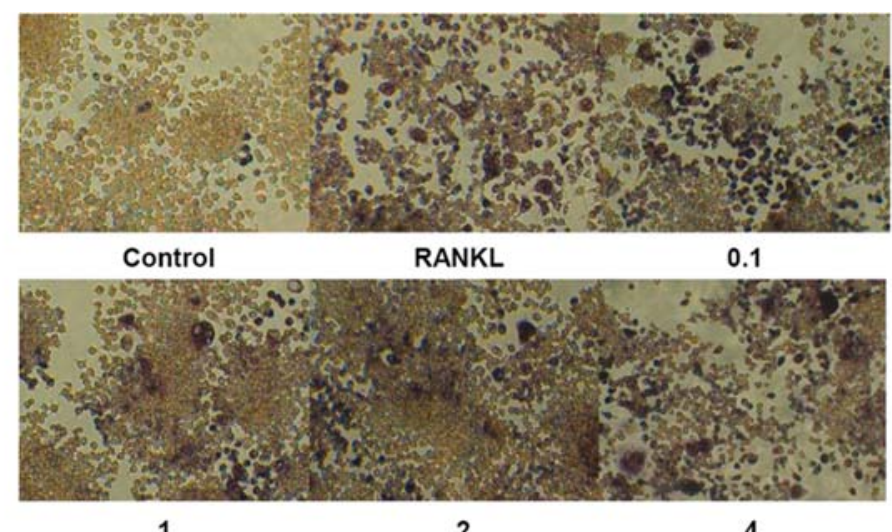

1

2

4

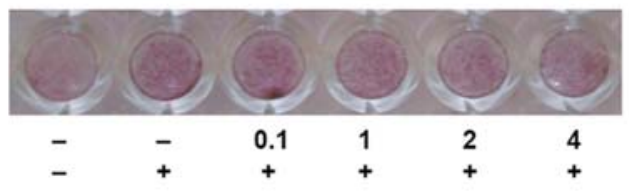
Omeprazole $(\mu \mathrm{g} / \mathrm{ml})$
RANKL $(50 \mathrm{ng} / \mathrm{ml})$

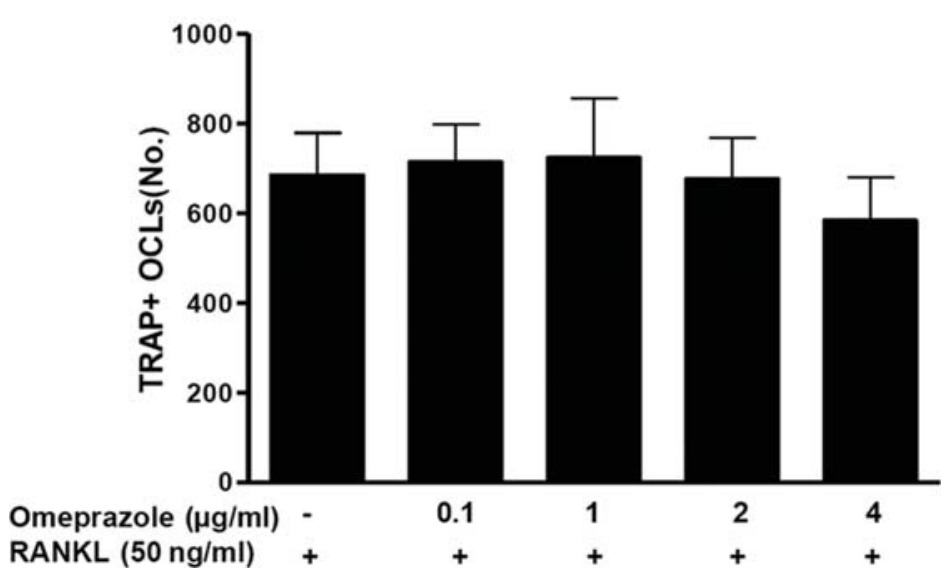

Figure 2. Effect of different concentrations of omeprazole on RAW 264.7 cell activation in the presence of RANKL. RAW 264.7 cell activation was measured by counting the number of TRAP-positive OCLs containing more than 3 nuclei using light microscopy. Cells were photographed at x 20 magnification. TRAP, tartrate-resistant acid phosphatase; OCL, osteoclast-like cell; RANKL, receptor activator of NF-кB ligand. 


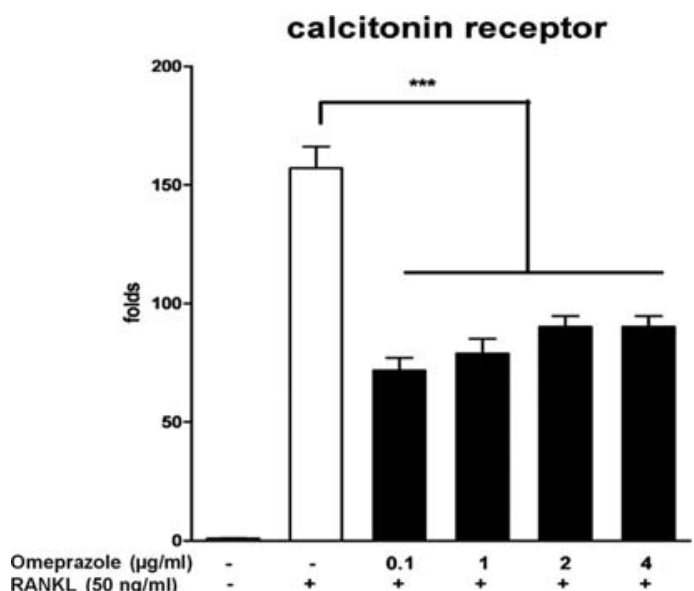

NFATc1

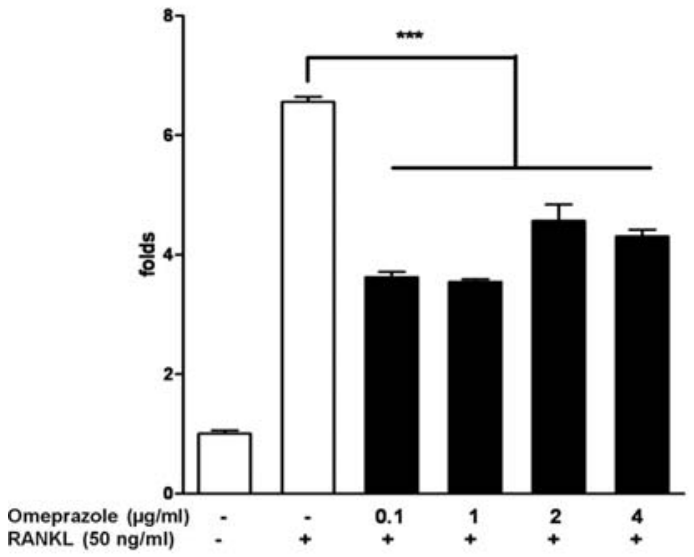

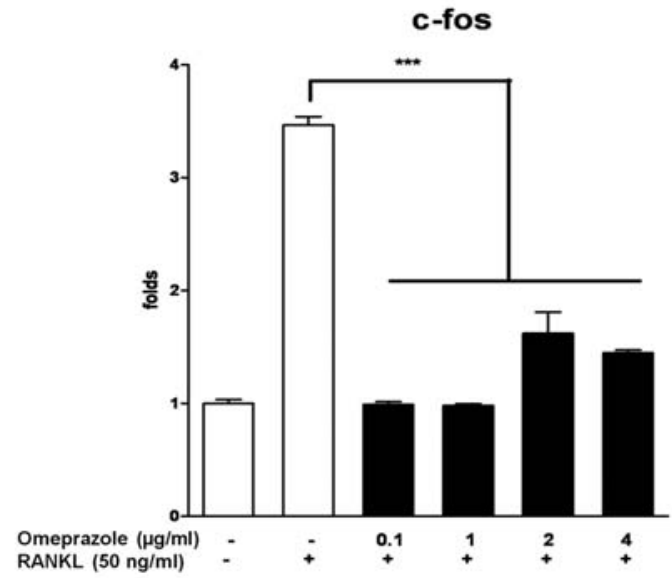

MMP9

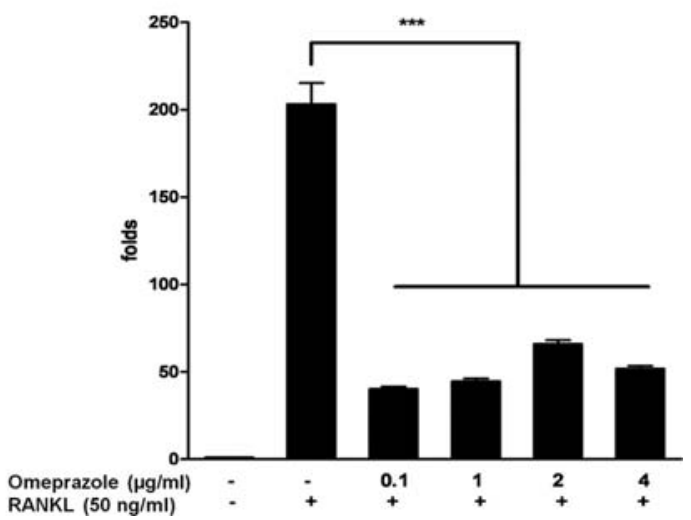

Figure 3. Effect of different concentrations of omeprazole on the fold-induction of transcription factor expression in activated RAW 264.7 cells. The expression of the transcription factors, calcitonin receptor, c-fos, NFATc1, and MMP-9 mRNA was assessed 3 days after culturing the RAW 264.7 cells in the presence of RANKL. Note how the fold induction of all the transcription factors significantly decreases regardless of the concentration of omeprazole. NFATc1, nuclear factor of activated T-cells, cytoplasmic 1; MMP-9, matrix metalloproteinase-9. ${ }^{* * *} \mathrm{P}<0.001 \mathrm{vs}$. control.

$1 \% \mathrm{NP} 40$, containing a mixture of proteinase inhibitors $(5 \mathrm{~g} / \mathrm{ml}$ aprotinin and $1 \mathrm{~g} / \mathrm{ml}$ leupeptin)] on ice using a homogenizer. An aliquot of the lysates was used to determine the protein concentration using the Bradford protein assay (Bio-Rad Laboratory, Richmond, CA, USA). An equal amount of lysates was run onto $12 \%$ SDS-polyacrylamide gels, and blotted to polyvinylidene difluoride membranes (Millipore Corporation, MA, USA). The membranes were blocked with $5 \%$ skim milk overnight at $4^{\circ} \mathrm{C}$, and incubated with antinuclear factor of activated T-cells, cytoplasmic 1 (NFATc1) or anti-matrix metalloproteinase (MMP)-9 monoclonal antibodies (Santa Cruz Biotechnology, Santa Cruz, CA). After three washes in TPBS $(0.05 \%$ Tween-20 in PBS), the blots were incubated with horseradish peroxidaseconjugated secondary antibodies. After extensive washing, the immune complexes were detected using the ECL system (Amersham Pharmacia Biotech, Piscataway, NJ). Omeprazole concentrations used for Western blotting were $0.1,1,2$, and $4 \mu \mathrm{g} / \mathrm{ml}$.

Statistical analysis. The significance of the results was tested using the two-way analysis of variance using commercially available software (Graphpad Prism; GraphPad Software, San Diego, CA). A P-value $<0.05$ was considered statistically significant.

\section{Results}

MTT assay. Measurement of the cell viability by the MTT assay demonstrated that omeprazole at concentrations of 0.1 , 1,2 , and $4 \mu \mathrm{g} / \mathrm{ml}$ did not significantly affect the number of RAW 264.7 cells compared to the control. The number of MC3T3-E1 cells also showed no difference between the control and those treated with omeprazole at the aforementioned concentrations (Fig. 1).

TRAP assay. The number of TRAP positive multinucleated cells, which are osteoclast-like cells (OCLs) containing more than 3 nuclei were identified as activated RAW 264.7 cells and counted under a light microscope. OCL formation in RAW 264.7 cells measured by TRAP positivity at omeprazole concentrations of $0.1,1,2$, and $4 \mu \mathrm{g} / \mathrm{ml}$, showed a decreasing, but not statistically significant trend as the concentration of omeprazole increased (Fig. 2). 

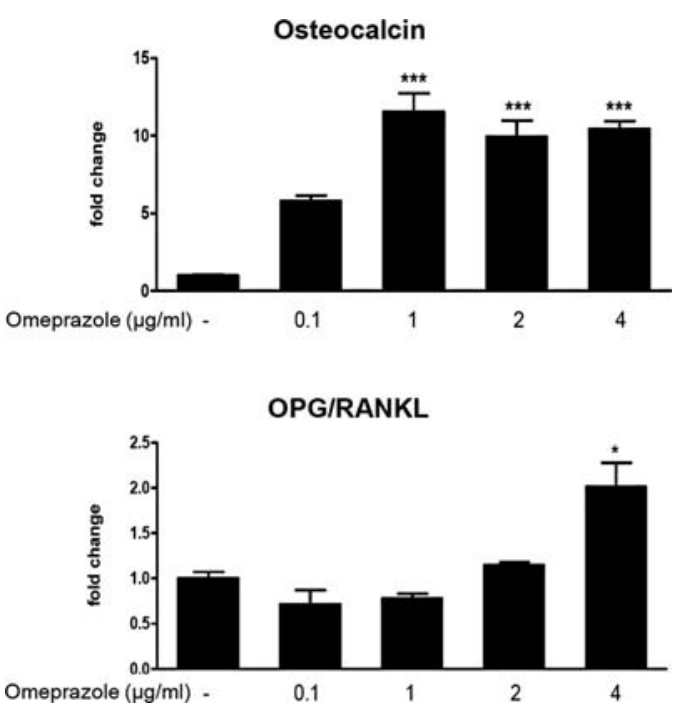

Figure 4. Effect of omeprazole on the fold changes of osteocalcin gene expression and OPG/RANKL ratio. The levels of osteocalcin gene expression and OPG/RANKL ratio were measured after culturing MC3T3-E1 cells for 12 days. OPG, osteoprotegerin; RANKL, receptor activator of $\mathrm{NF}-\kappa \mathrm{B}$ ligand. ${ }^{*} \mathrm{P}<0.05,{ }^{* * *} \mathrm{P}<0.001$ vs. control.

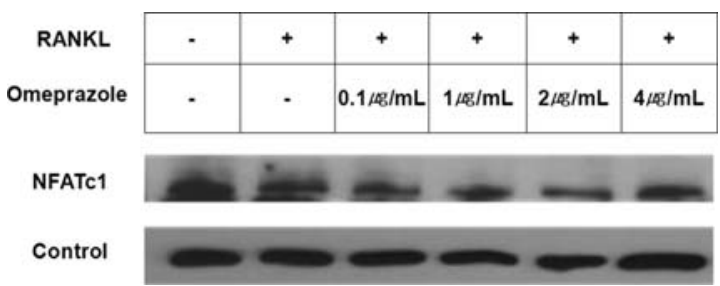

Figure 5. Effect of different concentrations of omeprazole on the translation of the NAFTc1 gene in activated RAW 264.7 cells. Western blot analysis was done to assess the translation of NFATc1 gene in RAW 264.7 cells cultured in the presence of RANKL. Note how the translation of the NFATc1 gene decreases with increasing dose of omeprazole, consistent with the result of the gene expression of NFATc1 mRNA.

Gene expression. The expression of calcitonin receptor (CTR) mRNA in OCLs was evaluated on day 3 by measuring the fold induction of CTR. After adding RANKL to the RAW 264.7 cells, in the absence of omeprazole, there was a 155.42-fold increase in CTR gene expression. When 0.1, 1, 2 , and $4 \mu \mathrm{g} / \mathrm{ml}$ of omeprazole were added, CTR gene expression decreased to 64.89-, 66.87-, 78.07-, and 81.20fold, respectively, and this decrease in fold induction was statistically significant compared to when only RANKL was added $(\mathrm{P}<0.001)$ (Fig. 3). The expression of $\mathrm{c}$-fos and NFATc1 mRNA assessed 3 days after culturing the RAW 264.7 cells in the presence of RANKL also showed an increase to 3.47- and 6.56-fold, respectively. When omeprazole was additionally added to the wells, the expression of c-fos mRNA decreased to 0.99-, 0.98-, 1.59-, and 1.44 -fold in the presence of $0.1,1,2$, and $4 \mu \mathrm{g} / \mathrm{ml}$ of omeprazole, respectively. The expression of NFATc1 mRNA also decreased to 3.62-, 3.55-, 4.55-, and 4.31-fold, respectively, at the aforementioned concentrations of omeprazole. The decrease of c-fos and NFATc1 mRNA in the presence of omeprazole was statistically significant regardless of the concentration of omeprazole $(\mathrm{P}<0.001$ for both) (Fig. 3). A similar trend was observed with the expression MMP-9 mRNA. MMP-9 expression increased to 202.25-fold in the presence of RANKL and decreased to 40.13-, 44.53-, 65.80-, and 51.63-fold with the treatment of omeprazole, showing a statistically significant decrease in fold induction $(\mathrm{P}<0.001)$ at each concentration of omeprazole (Fig. 3).

The levels of osteocalcin gene expression and the osteoprotegerin (OPG)/RANKL ratio were measured on day 12 after culturing the MC3T3-E1 cells. Treatment with omeprazole at concentrations of $0.1,1,2$, and $4 \mu \mathrm{g} / \mathrm{ml}$, increased osteocalcin expression to 5.79-, 11.45-, 9.85- and 10.43-fold, respectively. As for the OPG/RANKL expression ratio, it decreased to 0.68 - and 0.78 -fold, respectively, at concentrations 0.1 and $1 \mu \mathrm{g} / \mathrm{ml}$ of omeprazole, but it increased to 1.15 - and 1.98 -fold at concentrations 2 and $4 \mu \mathrm{g} / \mathrm{ml}$ of omeprazole, respectively (Fig. 4).

Western blot analysis. Western blot analysis was done for NFATc1 and the result was similar to that of the gene expression of NFATc1 mRNA in which the translation was decreased after the addition of omeprazole; this decrease in translation was seen regardless of the concentrations of omeprazole $(0.1,1,2$, and $4 \mu \mathrm{g} / \mathrm{ml})$ (Fig. 5).

\section{Discussion}

In this study, we have shown that omeprazole decreases the activation of osteoclasts but somewhat increases the activation of osteoblasts. Evidence that omeprazole decreases the activation of osteoclasts is that in RAW 264.7 cells expression of c-fos, NFATc1, and MMP-9 mRNA significantly decreased in the presence of omeprazole regardless of its concentration (Fig. 3). In addition, Western blot analysis of NFATc1 demonstrated that omeprazole treatment not only decreased the transcription but also the translation of NFATc1, one of the transcription factors studied (Fig. 5). Evidence that omeprazole increases the activation of osteoblasts is that the osteocalcin gene expression and the OPG/RANKL ratio in MC3T3-E1 cells increased along with increasing concentrations of omeprazole (Fig. 4).

Since in the presence of omeprazole the activity of osteoclasts decreases and that of osteoblasts increases, omeprazole seems to be osteoprotective in terms of decreasing bone resorption, possibly leading to an increase in bone mineral density, to the prevention of osteoporosis, and probably resulting in a decreased risk of bone fractures. However, several large population-based epidemiological studies have demonstrated that PPIs were not osteoprotective but rather increased the risk of bone fractures (7-12) especially when used for a long duration $(7,8)$ and at a high doses $(7,10)$.

The exact mechanism of how PPIs are related to an increased risk of bone fractures is not yet known but investigations are focused on two possible mechanisms. The first mechanism focuses on calcium homeostasis. Dietary calcium is classified as soluble (calcium citrate) and insoluble (calcium carbonate, calcium phosphate). For 
calcium to be absorbed into the the small intestine, it first has to be dissolved from its complexes or from the salt. This solubility of the calcium salts is $\mathrm{pH}$-dependent, meaning that low $\mathrm{pH}$ is mandatory for calcium salt dissolution (23). Therefore, some propose that the blockage of acid secretion by PPIs hinders absorption of calcium which results in an increased risk of bone fracture (13). This finding has also been noted in a small randomized crossover trial by O'Connell et al in which a reduction of fractional calcium absorption was observed in those taking PPIs (14). Since the most frequently prescribed calcium supplement is calcium carbonate, which needs a low $\mathrm{pH}$ for better absorption, acid blockage with PPIs could pose a problem. In addition, secondary hypergastrinemia due to acid suppression by PPIs may induce hyperparathyroidism and result in increased bone resorption $(15,16)$. The second mechanism focuses on the cells of bone turnover, especially the osteoclasts. It is well known that proton pumps in gastric parietal cells and osteoclasts are different; the proton pump in gastric parietal cells is the $\mathrm{H}^{+} / \mathrm{K}^{+}$-ATPase whereas that in osteoclasts is the vacuolar $\mathrm{H}^{+}$-ATPase (24). However, omeprazole, a representative of PPIs, has been shown to block not only the $\mathrm{H}^{+} / \mathrm{K}^{+}$ATPase but also the vacuolar $\mathrm{H}^{+}$-ATPase (17-19). Acid secretion by the proton pump vacuolar $\mathrm{H}^{+}$-ATPase in osteoclasts is essential for bone resorption, because the secreted hydrogen ion decalcifies the bone and activates the proteolytic enzymes which degrade the bone matrix. Since an essential step in bone resorption is blocked, bone mineral density should increase resulting in prevention or reduction of osteoporosis, and thus should lead to a decreased risk of bone fractures. The results of our study in which omeprazole decreased the activation of osteoclasts and increased the activation of osteoblasts also support an omeprazole-induced decreased risk of bone fractures. However, as has been previously mentioned, there is a discrepancy between the results obtained from in vitro studies on osteoclasts and that of several large population-based studies. How can this discrepancy be explained?

A possible explanation to this discrepancy was proposed by Targownik et al in which the effects of PPIs blocking the vacuolar $\mathrm{H}^{+}$-ATPase of osteoclasts was compared with that of osteopetrosis (25). During the course of life, microfractures develop as a result of normal wear and tear, damage to the bone due to mechanical forces applied internally or externally, etc. As a result, osteoblasts and osteocytes secrete cytokines that recruit osteoclast precursors, thus commencing the process of bone remodeling. However, when the osteoclasts fail to function and the damage cannot be mended, the bone becomes brittle leading to decreased bone tensile strength and finally to fracture. An example of this defect is well demonstrated by a rare disease, osteopetrosis. Osteopetrosis is a genetic disease with various subtypes. Each subtype has its own typical clinical manifestations but the skeletal manifestations are common to all subtypes: increased bone density and fragility (26). In osteopetrosis, the bone matrix density increases but the bone remains brittle, being seemingly strong on the outside but actually weak on the inside. Therefore, since PPIs block the vacuolar $\mathrm{H}^{+}$-ATPase of osteoclasts and also inhibit the activity of osteoclasts, as has been shown in our study, it could be suggested that PPIs exert an osteopetrosis-like effect on the bone. This effect of PPIs together with their previously mentioned effect on calcium homeostasis, support the hypothesis that PPIs can produce a state resembling osteopetrorickets as reported by Schinke et al (27).

There are some limitations to this study. First, of the two main transcription factors needed for activating NFATc1, c-

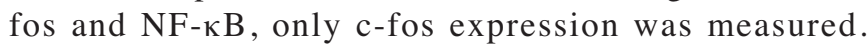
However, since $\mathrm{c}-\mathrm{fos}$ is induced by $\mathrm{NF}-\mathrm{\kappa B}$, if the expression of c-fos and NFATc1 has decreased, it could be postulated that the expression of $\mathrm{NF}-\kappa \mathrm{B}$ has also decreased and vice versa. Second, only the Western blotting of NFATc1 was performed. For a complete evaluation and to strengthen our findings, it would have been necessary to perform Western blot analysis of all the transcription factors analyzed in this study since transcription of a gene to mRNA does not always correlate with its translation to protein. Nevertheless, since NFATc1, the product of the last step in the signaling pathway and the master transcription factor for osteoclast differentiation is decreased, it could be conceivable to think that the prior transcription factors are decreased as well.

In conclusion, in addition to the well known effect of PPIs blocking the vacuolar $\mathrm{H}^{+}$-ATPase in osteoclasts, our study shows that omeprazole decreases the activation of osteoclasts as demonstrated by the decrease in the expression of transcription factors, and increases the activation of osteoblasts. Although further studies are warranted to fully clarify the underlying mechanism of the PPIs on bone metabolism and their link to bone fractures, our in vitro experiment suggests the possibility that one potential mechanism, through which PPIs could increase the risk of bone fractures, may be by inducing a state resembling osteopetrorickets.

\section{Acknowledgements}

This study was financially supported by Yuhan Corporation, Korea.

\section{References}

1. DeVault KR and Castell DO: Updated guidelines for the diagnosis and treatment of gastroesophageal reflux disease. Am J Gastroenterol 100: 190-200, 2005.

2. Bak YT: Management strategies for gastroesophageal reflux disease. J Gastroenterol Hepatol 19: S49-S53, 2004.

3. Soll AH: Consensus conference. Medical treatment of peptic ulcer disease. Practice guidelines. Practice Parameters Committee of the American College of Gastroenterology. JAMA 275: 622-629, 1996

4. Talley NJ and Vakil N: Guidelines for the management of dyspepsia. Am J Gastroenterol 100: 2324-2337, 2005.

5. Laheij RJ, Sturkenboom MC, Hassing RJ, Dieleman J, Stricker BH and Jansen JB: Risk of community-acquired pneumonia and use of gastric acid-suppressive drugs. JAMA 292: 1955-1960, 2004.

6. Dial S, Delaney JA, Barkun AN and Suissa S: Use of gastric acidsuppressive agents and the risk of community-acquired Clostridium difficile-associated disease. JAMA 294: 2989-2995, 2005.

7. Yang YX, Lewis JD, Epstein S and Metz DC: Long-term proton pump inhibitor therapy and risk of hip fracture. JAMA 296: 2947-2953, 2006.

8. Targownik LE, Lix LM, Metge CJ, Prior HJ, Leung S and Leslie WD: Use of proton pump inhibitors and risk of osteoporosis-related fractures. CMAJ 179: 319-326, 2008.

9. Vestergaard P, Rejnmark L and Mosekilde L: Proton pump inhibitors, histamine $\mathrm{H} 2$ receptor antagonists, and other antacid medications and the risk of fracture. Calcif Tissue Int 79: 76-83, 2006. 
10. Corley DA, Kubo A, Zhao W and Quesenberry C: Proton pump inhibitors and histamine-2 receptor antagonists are associated with hip fractures among at-risk patients. Gastroenterology 139: 93-101, 2010.

11. Yu EW, Blackwell T, Ensrud KE, et al: Acid-suppressive medications and risk of bone loss and fracture in older adults. Calcif Tissue Int 83: 251-259, 2008.

12. Gray SL, LaCroix AZ, Larson J, et al: Proton pump inhibitor use, hip fracture, and change in bone mineral density in postmenopausal women: results from the Women's Health Initiative. Arch Intern Med 170: 765-771, 2010.

13. Chonan O, Takahashi R, Yasui $\mathrm{H}$ and Watanuki M: Effect of L-lactic acid on calcium absorption in rats fed omeprazole. J Nutr Sci Vitaminol (Tokyo) 44: 473-481, 1998.

14. O'Connell MB, Madden DM, Murray AM, Heaney RP and Kerzner LJ: Effects of proton pump inhibitors on calcium carbonate absorption in women: a randomized crossover trial Am J Med 118: 778-781, 2005.

15. Yang YX: Proton pump inhibitor therapy and osteoporosis. Curr Drug Saf 3: 204-209, 2008.

16. Gagnemo-Persson R, Samuelsson A, Hakanson R and Persson P: Chicken parathyroid hormone gene expression in response to gastrin, omeprazole, ergocalciferol, and restricted food intake. Calcif Tissue Int 61: 210-215, 1997.

17. Xu J, Cheng T, Feng HT, Pavlos NJ and Zheng MH: Structure and function of V-ATPases in osteoclasts: potential therapeutic targets for the treatment of osteolysis. Histol Histopathol 22: 443-454, 2007

18. Mizunashi K, Furukawa Y, Katano K and Abe K: Effect of omeprazole, an inhibitor of $\mathrm{H}+, \mathrm{K}(+)$-ATPase, on bone resorption in humans. Calcif Tissue Int 53: 21-25, 1993.
19. Farina $C$ and Gagliardi S: Selective inhibition of osteoclast vacuolar H(+)-ATPase. Curr Pharm Des 8: 2033-2048, 2002.

20. Suh KS, Choi EM, Kwon M, et al: Kaempferol attenuates 2deoxy-d-ribose-induced oxidative cell damage in MC3T3-E1 osteoblastic cells. Biol Pharm Bull 32: 746-749, 2009.

21. Tintut Y, Parhami F, Tsingotjidou A, Tetradis S, Territo M and Demer LL: 8-Isoprostaglandin E2 enhances receptor-activated NFkappa B ligand (RANKL)-dependent osteoclastic potential of marrow hematopoietic precursors via the cAMP pathway. J Biol Chem 277: 14221-14226, 2002.

22. Pfaffl MW: A new mathematical model for relative quantification in realtime RT-PCR. Nucleic Acids Res 29: 2002-2007, 2001.

23. Ivanovich $\mathrm{P}$, Fellows $\mathrm{H}$ and Rich C: The absorption of calcium carbonate. Ann Intern Med 66: 917-923, 1967.

24. Jefferies KC, Cipriano DJ and Forgac M: Function, structure and regulation of the vacuolar $(\mathrm{H}+)$-ATPases. Arch Biochem Biophys 476: 33-42, 2008.

25. Targownik LE, Lix LM, Leung S and Leslie WD: Proton-pump inhibitor use is not associated with osteoporosis or accelerated bone mineral density loss. Gastroenterology 138: 896-904, 2009.

26. Tolar J, Teitelbaum SL and Orchard PJ: Osteopetrosis. N Engl J Med 351: 2839-2849, 2004.

27. Schinke T, Schilling AF, Baranowsky A, et al: Impaired gastric acidification negatively affects calcium homeostasis and bone mass. Nat Med 15: 674-681, 2009. 